\title{
Effects of Tai Chi Chuan on cognition of elderly women with mild cognitive impairment
}

\author{
Efeitos da prática de Tai Chi Chuan na cognição de idosas com comprometimento cognitivo leve
}

\author{
Juliana Yumi Tizon Kasai ${ }^{1}$, Alexandre Leopold Busse ${ }^{2}$, Regina Miksian Magaldi ${ }^{3}$, Maria Angela Soci ${ }^{4}$, \\ Priscilla de Moraes Rosa ${ }^{5}$, José Antônio Esper Curiati ${ }^{6}$, Wilson Jacob Filho ${ }^{7}$
}

\begin{abstract}
Objective: To detect the effects of Tai Chi Chuan practice on the cognition of elderly subjects with Mild Cognitive Impairment. Methods: This is a pilot study with 26 elderly patients (mean age of 74 years) with Mild Cognitive Impairment. The evaluation instruments were Subjective Memory Complaint Scale (SMC), Rivermead Behavioral Memory Test (RBMT) and Digit Span Forward and Backward (DSF and DSB) from the Wechsler Adult Intelligence Scale (WAIS). One group of 13 patients received two weekly 60minute classes of Tai Chi Chuan (Yang style) for 6 consecutive months, and the rest formed the Control Group. The Tai Chi Chuan Group was also evaluated as to learning of the Tai Chi Chuan practical exercises by means of a Specific Learning Test applied after three months of intervention. Results: After six months of intervention, the TCC Group showed significant improvement on the RBMT and the SMC ( $p=0.007$ and $p=0.023$, respectively). The Control Group showed no significant differences in the cognitive tests during the study. There was a significant correlation between the Tai Chi Chuan Learning Test and RBMT ( $p=0.008)$, showing that patients with a better performance in exercising TCC also showed a better performance in memory. Conclusions: In this study, a sixmonth program of Tai Chi Chuan afforded a significant improvement of the performance of memory complaints in the elderly with Mild Cognitive Impairment. Additional randomized studies with larger samples and more prolonged follow-up are needed to confirm these benefits.
\end{abstract}

Keywords: Tai ji; Health services for the aged/psychology; Pilot projects; Neuropsychological tests; Memory disorders/therapy; Alzheimer disease; Alzheimer disease/rehabilitation; Alzheimer disease/prevention \& control; Exercise movement techniques

\section{RESUMO}

Objetivo: Detectar os efeitos da prática de Tai Chi Chuan na cognição de idosas com comprometimento cognitivo leve. Métodos: Estudo piloto com 26 idosas (média de idade de 74 anos) com comprometimento cognitivo leve. Os instrumentos de avaliação foram: Escala Subjetiva de Queixas de Memória (EOM), Teste Comportamental de Memória de Rivermead (RBMT) e Amplitude de Dígitos Verbal Direta e Indireta (DD e DI, respectivamente) derivadas do Weschler Adult Intelligence Scale (WAIS). Um grupo de 13 pacientes recebeu duas aulas semanais de 60 minutos de Tai Chi Chuan (estilo Yang) por 6 meses consecutivos, e o restante formou o Grupo Controle. 0 grupo Tai Chi Chuan também foi avaliado quanto ao aprendizado da prática dos exercícios de Tai Chi Chuan através de um Teste de Aprendizado Específico aplicado após três meses de intervenção. Resultados: Após seis meses de intervenção, o grupo Tai Chi Chuan apresentou melhora significativa no RBMT e na EQM ( $p=0,007$ e $p=0,023$, respectivamente). 0 Grupo Controle não apresentou diferenças significativas nos testes cognitivos no decorrer do estudo. Houve correlação significativa entre 0 Teste de Aprendizado de Tai Chi Chuan e o RBMT $(p=0,008)$, apontando que os pacientes com melhor performance na prática de Tai Chi Chuan apresentaram melhor desempenho da memória. Conclusões: Neste estudo, um programa de seis meses de Tai Chi Chuan propiciou uma melhora significativa do desempenho e das queixas de memória de idosas com comprometimento cognitivo leve. Estudos adicionais randomizados com casuística maior e seguimento mais prolongado são necessários para confirmar estes benefícios.

Descritores: Tai ji; Serviços de saúde para idosos/psicologia; Projetos piloto; Testes neuropsicológicos; Transtornos da memória/terapia; Doença de Alzheimer; Doença de Alzheimer/reabilitação; Doença de Alzheimer/prevenção e controle; Técnicas de exercício e de movimento

\footnotetext{
Study carried out at Serviço de Geriatria do Hospital das Clínicas, Faculdade de Medicina da Universidade de São Paulo - USP, São Paulo (SP), Brazil.

${ }^{1}$ Assistant physician of the Department of Geriatrics of the Hospital das Clínicas of Faculdade de Medicina da Universidade de São Paulo - USP, São Paulo (SP), Brazil.

${ }^{2}$ PhD; Assistant physician of the Department of Geriatrics of Faculdade de Medicina da Universidade de São Paulo - USP, São Paulo (SP), Brazil.

${ }^{3}$ Assistant physician of the Department of Geriatrics of the Hospital das Clínicas of Faculdade de Medicina da Universidade de São Paulo - USP, São Paulo (SP), Brazil.

${ }^{4}$ Physical educator; Director of the Sociedade Brasileira de Tai Chi Chuan - São Paulo (SP), Brazil.

${ }^{5}$ Physical therapist; Teacher of Tai Chi Chuan of the Sociedade Brasileira de Tai Chi Chuan - São Paulo (SP), Brazil.

${ }^{6} \mathrm{PhD}$; Assistant physician of the Department of Geriatrics of Faculdade de Medicina da Universidade de São Paulo - USP, São Paulo (SP), Brazil.

${ }^{7}$ Full professor of Geriatrics of the Faculdade de Medicina of Universidade de São Paulo - USP, São Paulo (SP), Brazil.

Corresponding author: Juliana Yumi Tizon Kasai - Rua Oscar Freire, 1967, apto. 81-A - Pinheiros - CEP 05409-011 - São Paulo (SP), Brazil - Tel.: $113582-0462$ - e-mail: julianayumi@eintein.br

Received on Aug 14, 2009 - Accepted on Jan 18, 2010
} 


\section{INTRODUCTION}

In Western societies, dementia is among the main causes of loss of functional capacity and autonomy in elderly individuals. With the aging of population, the number or persons in the world with Alzheimer's disease (AD) has been increasing considerably. Therefore, efforts have been made to identify the individual at a high risk of developing Alzheimer's disease and to test interventions that prevent or retard the manifestation of the disease ${ }^{(1)}$.

The need for an effective therapy, especially during the initial stages of the disease of the so-called Mild Cognitive Impairment (MCI) has been the focus of various studies. Patients without a diagnosis of dementia, but with some form of objective evidence of cognitive decline, are considered as having mild cognitive impairment ${ }^{(2)}$.

There is no consensus, however, as to the instruments for neuropsychological evaluation and diagnostic criteria $^{(3)}$. Observational studies suggest that the elderly with no dementia, but with a decline in memory objectively reported or demonstrated, show a greater risk of developing Alzheimer's disease over time ${ }^{(4-5)}$. Some medications have already been tested and afford benefits in the treatment of dementia, but this has not been demonstrated yet in individuals with $\mathrm{MCI}^{(6-7)}$. Thus, cognitive rehabilitation through nonpharmacological means is increasingly being sought ${ }^{(8)}$.

Currently, interest has grown as to the role of risk factors related to the individual's lifestyle (such as smoking, diet, and sedentary life) in the prevention of memory deficit and dementia ${ }^{(9-11)}$. A systematic review of 18 longitudinal studies (1966 to 2001) concluded that aerobic exercises provide consistent benefits to cognitive performance in sedentary elderly people $^{(12)}$.

Physical exercises have well-defined effects on the health of the elderly, but the appropriate forms of practicing them are scarce, since aging is accompanied by an organic decline, such as a wearing of the joints, visual deficits, balance modifications, and lowered muscular resistance. Various literature reports suggest that Tai Chi Chuan has the characteristics necessary for appropriate physical exercise in the elderly ${ }^{(13)}$.

Tai Chi Chuan was originally developed as a martial art, but it has been practiced for centuries in China as a physical activity, primarily by the elderly population, due to its low impact and low speed ${ }^{(14)}$. This millennial practice consists in the execution of gentle circular movements associated with breathing, concentration, and relaxation exercises ${ }^{(15)}$. Various prior studies have classified Tai Chi Chuan as a moderate intensity exercise, since its practice makes the individual reach $60 \%$ of the maximal heart rate and $55 \%$ of the maximal uptake of oxygen $^{(14,16)}$.

A variety of benefits related to Tai Chi Chuan was described. Numerous studies demonstrated a positive impact of Tai Chi Chuan on balance, muscular strength, flexibility, posture control, and consequently on the prevention of falls in the elderly ${ }^{(13-15,17-18)}$.

One recently published study showed that the group that practiced Tai Chi Chuan displayed improvement in learning and in memory when compared to the Control Group after one year. These results suggest that, besides improving memory performance, Tai Chi Chuan may retard its alterations during the aging process ${ }^{(19)}$.

\section{OBJECTIVE}

Considering the known benefits of Tai Chi Chuan, this paper was developed in order to assess the effects of this practice on the cognition of the elderly with mild cognitive impairment, a theme that is still practically unexplored.

\section{METHODS}

\section{Inclusion criteria}

Elderly women aged 60 years or more; absence of programmed physical exercise over the previous 12 months; memory complaint offered by the patient or by family members over the previous year; screening score of the Rivermead Behavioral Memory Test lower than 10; Mini Mental State Examination (MMSE) within normality, corrected by educational level ${ }^{(20)}$; Geriatric Depression Scale (GDS) within normality ${ }^{(21)}$; functionality preserved in basic and instrumental activities of daily life ${ }^{(22-23)}$.

\section{Exclusion and non-inclusion criteria}

Presence of clinical criteria for dementia, depression, and anxiety by the criteria of the Diagnostic and Statistical Manual of Mental Disorders of the American Association of Psychiatry (DSM IV) (24); chronic alcoholism; serious psychiatric disorders; cranioencephalic trauma or cerebrovascular accident occurred in the previous year; use of medications that interfere in cognition (antidepressants, anxiolytics, antipsychotics, opiates, anti-vertigo drugs, antiParkinson agents, anticonvulsants); clinical conditions that contraindicate light physical exercise, as per the American Heart Association; serious auditory and/or visual deficit; significant changes in ancillary tests such as blood glucose, sodium, potassium, urea, calcium, magnesium, complete blood count, erythrocyte 
sedimentation rate, liver enzymes, thyroid hormones, serology for syphilis, folic acid, and vitamin B12.

After signing the informed consent form, the elderly women included in the study were non-randomly distributed into an intervention group with Tai Chi Chuan classes $(n=13)$ and a Control Group $(n=13)$. The control group was instructed not to practice Tai Chi Chuan until the end of the study. Both groups were assessed at the beginning of the study and after three and six months. The female gender was chosen because of the dominance of this sex in the elderly population, which would facilitate the recruitment of research subjects.

\section{Assessment instruments}

The Subjective Memory Complaints Scale (SMC) is derived from the Cambridge Examination for Mental Disorders of the Elderly (CAMDEX) and was developed so that the greater the number of complaints, and the greater interference these had in the individual's life, the greater was the punctuation from zero to 21 . This test evaluates the perception of memory by the patient herself ${ }^{(25)}$.

The Rivermead Behavioral Memory Test (RBMT) is composed of a series of practical tasks seeking to simulate daily life situations, thus diminishing the interference of cultural or educational level factors. This test is divided into two scores: Screening (SCR) and Standard Profile (SDP). The screening score varied from zero to 12 points (normal: greater than or equal to 10) and was used as an inclusion criterion. The more detailed standard profile varied from zero to 24 points (normal: greater than or equal to 22), and is more appropriate for memory follow-up. Values below the cutoff scores indicate cognitive impairment ${ }^{(26)}$.

The test is composed of the following items: name and last name (recognition of name and last name from a photograph); hidden belonging (remembering to ask for a belonging to be returned); appointment (asking a question when an alarm goes off); pictures (recognizing familiar pictures); immediate and delayed story (memorizing a story immediately and after a few minutes), immediate and delayed route (memorizing a route sequence through the evaluation room immediately and after a few minutes); message (leaving a message in the middle of the path in a specific place), orientation (temporospatial orientation and general knowledge questions, such as the name of the current president) and date (correctly evoking the day, month, and year). Classifications vary according to the score: normal, weak memory, moderate impairment, and serious impairment ${ }^{(26)}$.
The Digit Span Forward (DSF) and Backward (DSB) tests derived from the Wechsler Adult Intelligence Scale (WAIS) consist in the repetition of verbally given digit sequences in the forward and backward orders. They measure the capacity for concentration and working memory, respectively. The number of digits increases over the time of testing, until the subject fails in two consecutive sequences of a certain number of digits ${ }^{(27)}$.

After three months of intervention, the Tai Chi Chuan group was evaluated as to learning of the Tai Chi Chuan activities by means of a specific quantitative test. This test was drawn up and applied by the Brazilian Society of Tai Chi Chuan, varying from zero to 10 for each Tai Chi Chuan posture performed.

\section{Intervention}

After approval by the Research Ethics Committee, the study was carried out at the Elderly Memory Outpatient Clinic (AMI, acronym in Portuguese) of the Geriatrics Department of Hospital das Clínicas of Faculdade de Medicina da USP. The 60-minute Tai Chi Chuan classes (Yang style) were given by a physical therapist twice a week. After warm-up, the exercises focused on muscular strength, improvement of flexibility, motor coordination, and control of concentration and breathing. The intensity and complexity of the exercises increased over time during the study.

The patients were also instructed to practice the exercises at home, using a didactic brochure. If they missed a class, the teacher recommended increasing the frequency of exercises at home.

\section{Statistical analysis}

In order to compare the means between the groups as to the continuous variables, the Student's $t$ test was used. Kolmogorov-Smirnov tests were used to verify if the scales in each group showed normal distribution, and the test did not reject the normality of distributions for any of the scales at the three time points observed. Variance analyses (ANOVA) were performed with repeated measurements and two factors, in which the group (control or intervention) was the fixed factor and the time point (initial, three months, and six months) was the repetition factor.

\section{RESULTS}

The samples were similar in the age, schooling and initial cognitive assessments (RBMT, SMC, DSF, and $\mathrm{DSB})$ variables, as shown on table 1 . There were two losses in the TCC group after three months of the study due to drop-out and uncontrolled hypothyroidism. 
Table 1. Baseline characteristics of the sample

\begin{tabular}{lccc}
\hline Characteristics & $\begin{array}{c}\text { Tai Chi Group } \\
(\mathbf{n}=\mathbf{1 3})\end{array}$ & $\begin{array}{c}\text { Control Group } \\
(\mathbf{n}=\mathbf{1 3})\end{array}$ & p value* \\
\hline Age (years) & 73.54 & 74.54 & 0.838 \\
Schooling (years) & 5.31 & 3.15 & 0.115 \\
Rivermead test (RBMT) & 15.31 & 15.15 & 0.902 \\
Complaint scale (SMC) & 9.00 & 7.92 & 0.387 \\
Digit Span Forward (DSF) & 5.62 & 4.62 & 0.110 \\
Digit Span Backward (DSB) & 4.31 & 3.77 & 0.507 \\
\hline
\end{tabular}

RBMT: Rivermead Behavioral Memory Test; SMC: Subjective Memory Complaint Scale; DSF: Digit Span Forward; DSB: Digit Span Backward.

*Matched $t$ test

The TCC group showed a significant increase in the mean Rivermead Test (RBMT) scores after six months $(\mathrm{p}=0.007)$, indicating a major improvement in memory performance for the elderly women who practiced Tai Chi Chuan in comparison to the Control Group (Table 2).

Table 2. Description of the cognitive scale among groups and time points

\begin{tabular}{llccccccc}
\hline \multirow{2}{*}{ Scale } & \multirow{2}{*}{ Group } & \multicolumn{2}{c}{ Baseline } & \multicolumn{2}{c}{ 3 months } & \multicolumn{2}{c}{$\mathbf{6}$ months } & \multirow{2}{*}{ ( value* } \\
& & Mean & SD & Mean & SD & Mean & SD & \\
\hline \multirow{2}{*}{ RBMT } & Control & 15.15 & 2.85 & 16.69 & 2.18 & 14.54 & 3.86 & \multirow{2}{*}{0.007} \\
& Tai Chi & 15.31 & 3.45 & 19.92 & 4.05 & 19.09 & 4.39 & \\
\multirow{2}{*}{ SCM } & Control & 7.92 & 3.04 & 7.23 & 2.35 & 7.77 & 2.65 & \multirow{2}{*}{0.023} \\
& Tai Chi & 9.00 & 3.19 & 5.54 & 3.07 & 5.64 & 3.78 & \\
\multirow{2}{*}{ DSF } & Control & 4.62 & 1.33 & 4.54 & 1.05 & 4.54 & 1.33 & \multirow{2}{*}{0.164} \\
& Tai Chi & 5.62 & 1.71 & 6.38 & 3.12 & 6.91 & 2.63 & \\
\multirow{2}{*}{ DSB } & Control & 3.77 & 1.54 & 3.31 & 1.60 & 4.00 & 1.47 & \multirow{2}{*}{0.031} \\
& Tai Chi & 4.31 & 2.43 & 4.85 & 2.38 & 4.55 & 2.42 & \\
\hline
\end{tabular}

RBMT: Rivermead Behavioral Memory Test; SMC: Subjective Memory Complaint Scale; DSF: Digit Span Forward; DSB: Digit Span Backward; SD: standard deviation. *Variance analyses (ANOVA).

The TCC group showed a significant drop in memory complaints $(p=0.023)$,i.e., there was marked improvement in complaints regarding memory (perception of memory) in the elderly patients who practiced Tai Chi Chuan relative to the controls. The DSF scale showed a significant difference in the ANOVA analysis, suggesting a difference in working memory between the two groups that was evident in the third month of the study $(\mathrm{p}=0.031)$. On the other hand, there was no significant difference on the DSB scale $(p=0.164)$, and, therefore, no improvement was noted in the attention and concentration of the elderly women who practiced Tai Chi Chuan in comparison to the Control Group in the present study.

There was a direct correlation between the Learning Tai Chi Chuan Test and the score means of the RBMT (Pearson's correlation coefficient) in the TCC Group ( $\mathrm{p}$ $=0.008)$, which reinforces the direct relation between memory performance and the practice of Tai Chi Chuan in this study.

\section{DISCUSSION}

The results showed a significant difference in RBMT after intervention in the TCC Group, which reveals a significant improvement in memory performance of the elderly patients who practiced Tai Chi Chuan. It is important to point out that RBMT is a test with four different versions, which facilitates the longitudinal follow-up for measuring loss of memory and to monitor the effects of cognitive rehabilitation, without suffering the influence of schooling, age, or gender, and with a reduced effect of learning. There was also a significant difference in the SMC of the intervention group, i.e., the elderly women who practiced Tai Chi Chuan had a decrease in complaints related to memory.

Studies involving the cognitive function and Tai Chi Chuan are still scarce in the medical literature. Most studies associate aerobic physical exercise and cognition in the elderly population. Various studies have classified Tai Chi Chuan as a moderate intensity physical activity, since $60 \%$ of the maximal heart rate is reached, along with $55 \%$ of the maximal oxygen uptake ${ }^{(14,16)}$. Therefore, the positive results found in the present study are related to the fact that Tai Chi Chuan, besides being considered as a physical exercise, works on concentration in performing a long sequence of movements (the sequence of movements requires memorization), maintaining the focus on body consciousness, relaxation, and breathing. This hypothesis is reinforced by the direct correlation found in this study between the Tai Chi Chuan Learning Test and the mean scores of RBMT in the TCC group, which reinforces the direct relation between memory performance and the practice of Tai Chi Chuan.

In a systematic review by Cochrane Collaboration, the efficacy of aerobic physical exercise in the cognitive function of the elderlywithout prior cognitive impairment was assessed. Eleven controlled randomized trials with participants aged 55 years or older were selected. The conclusion was that there is evidence that aerobic physical exercise is beneficial for the cognitive function in the elderly, with effects observed on motor function, cognitive speed, and attention. Nevertheless, data are insufficient to demonstrate that the improvement in cognitive function is due to an improvement in cardiovascular aptitude. Additional studies are needed to confirm if the aerobic training is necessary, or if the benefit may be attained with any type of physical exercise $^{(28)}$.

In a randomized clinical trial involving 32 elderly subjects with cognitive impairment, a significant cognitive improvement (RBMT) was also observed in the group that participated in a resistance exercise program (muscle building) for nine months, but no improvement was observed as to memory complaints, as in the present study involving Tai Chi Chuan. Working memory, attention, and concentration presented no significant differences related to muscle building 
activities, results that are similar to those of the study presented with Tai Chi Chuan ${ }^{(8)}$.

Positive results relating Tai Chi Chuan and cognitive improvements were found in a study by Chan et al. that compared the cognitive function of 4 distinct groups after 12 months $(n=140$, age over 56 years, with no prior cognitive modifications): Tai Chi Chuan group, physical activity group (dancing and tennis), Tai Chi Chuan plus physical activity group, and control group (no programmed activity). The assessment instruments for this study were the Hong Kong List Learning Test (a memory scale validated in China) and a modified scale version of the Boston Naming Test. The findings revealed a significant association between the practice of Tai Chi Chuan and/or physical activity with better performance in cognitive tests compared to the control group, including learning, memory retention, and repetition. These data suggest that both Tai Chi Chuan and the other types of physical activity help to preserve cognitive function in elderly adults. The elderly that practiced Tai Chi Chuan plus physical activity showed better performances on the tests compared to the group that only practiced Tai Chi Chuan, which indicates that different types of exercises may have different effects on the functions of memory.

The group that practiced Tai Chi Chuan showed greatest memory preservation after one year, with a significant difference relative to the other groups. These findings, as those in the present study, suggest that Tai Chi Chuan plays an important role in the cognition of elderly individuals and might have a protective effect against dementia, although more studies are necessary to confirm these data ${ }^{(19)}$.

Despite the encouraging results of this research, some limitations must be considered. An adequate randomization of the sample and the cognitive assessment made by a blind examiner would produce more consistent results. On the other hand, the small sample size and the short follow-up time, considering that the technique utilized demands a long learning period for optimal results, may have negatively influenced the results.

\section{CONCLUSIONS}

The findings of the present study suggest that the sixmonth practice of Tai Chi Chuan is related to a significant improvement of the memory and self-perception (reported complaints) of the memory in elderly women with mild cognitive impairment.

Further randomized studies with larger samples and longer follow-up are needed to test the effects identified in this study and to explore the potential of Tai Chi Chuan practice in the prevention and treatment of cognitive decline in the elderly population.

\section{REFERENCES}

1. Lautenschlager NT, Cox KL, Flicker L, Foster JK, van Bockxmeer FM, Xiao J, et al. Effect of physical activity on cognitive function in older adults at risk for alzheimer disease: a randomized trial. JAMA. 2008;300(9):1027-37.

2. Thal LJ. Therapeutics and mild cognitive impairment: current status and future directions. Alzheimer Dis Assoc Disord. 2003;17(Suppl 2):S69-71.

3. Busse A, Bischkopf J, Riedel-Heller SG, Angermever MC. Mild cognitive impairment: prevalence and incidence according to different diagnostic criteria. Results of the Leipzig Longitudinal Study of the Aged (LEILA75+). Br J Psychiatry. 2003;182:449-54.

4. van Oijen M, de Long FJ, Hofman A, Koudstaal PJ, Breteler MM. Subjective memory complaints, education, and risk of Alzheimer's disease. Alzheimers Dement. 2007;3(2):92-7.

5. Petersen RC. Mild cognitive impairment as a diagnostic entity. J Intern Med. 2004;256(3):183-94.

6. Loy C, Schneider L. Galantamine for Alzheimer's disease and mild cognitive impairment (Cochrane Review). In: The Cochrane Library, Issue 3, 2007. Oxford: Update Software.

7. Birks J, Grimley EJ, lakovidou V, Tsolaki M. Rivastigmine for Alzheimer's disease (Cochrane Review). In: The Cochrane Library, Issue 3, 2007. Oxford: Update Software.

8. Busse AL, Jacob Filho W, Magaldi RM, Coelho VA, Melo AC, Betoni RA, et al. Effects of resistance training exercise on cognitive performance in the elderly individuals with memory impairment: results of a controlled trial. einstein. 2008;6(4):402-7.

9. Jorm AF. Prospects for the prevention of dementia. Aust $J$ Ageing. 2002;21(1):9-13.

10. Lautenschlager NT, Almeida OP, Flicker L, Janca A. Can physical activity improve the mental health of older adults? Ann Gen Hosp Psychiatry. 2004;3(1):12.

11. Fratigliono L, Paillard-Borg S, Winblad B. An active and socially integrate lifestyle in late life might protect against dementia. Lancet Neurol. 2004;3(6):343-53.

12. Colcombe $S$, Kramer AF. Fitness effects on the cognitive function of older adults: a meta-analytic study. Psychol Sci. 2003;14(2):125-30.

13. Li JX, Hong Y, Chan KM. Tai Chi: physiological characteristics and beneficial effects on health. Br J Sports Med. 2001;35(3):148-56.

14. Zhang JG, Ishikawa-Takata K, Yamazaki H, Morita T, Ohta T. The effects of Tai-Chi-Chuan on physiological function and fear of falling in the less robust elderly: an intervention study for preventing falls. Arch Gerontol Geriatr. 2006;42(2):107-16.

15. Wang C, Collet JP, Lau J. The effects of Tai Chi on health outcomes in patients with chronic conditions: a systematic review. Arch Intern Med. 2004;164(5):493-501.

16. Verhagen AP, Immink M, van der Meulen A, Bierma-Zeinstra SM. The efficacy of Tai Chi Chuan in older adults: a systematic review. Fam Pract. 2004;21(1):10713.

17. Li F, Harmer P, Fisher KJ, McAuley E. Tai Chi: improving functional balance and predicting subsequent falls in older persons. Med Sci Sports Exerc. 2004;36(12):2046-52.

18. Thornton EW, Sykes KS, Tang WK. Health benefits of Tai Chi exercise: improved balance and blood pressure in middle-aged women. Health Promot Int. 2004;19(1):33-8.

19. Chan AS, Ho YC, Cheung MC, Albert MS, Chiu HF, Lam LC. Association between mind-body and cardiovascular exercises and memory in older adults. J Am Geriatric Soc. 2005;53(10):1754-60.

20. Folstein MF, Folstein SE, McHugh PR. "Mini-Mental State". A practical method for grading the cognitive state of patients for the clinician. J Psychiatr Res. 1975;12(3):189-98.

21. Yesavage JA, Brink TL, Rose TL, Lum O, Huang V, Adev M, et al. Development and validation of a geriatric depression screening scale: a preliminary report. J Psychiatr Res. 1982-1983;17(1):37-49. 
22. Lawton MP. The function assessment of the elderly people. J Am Geriatr Soc. 1971;19(6):465-81.

23. Katz S, Akpom CA. Index of ADL. Med Care. 1976;14(5 Suppl):116-8.

24. American Psychiatric Association. Diagnostic and Statistical Manual of Mental Disorders. 4th ed. Washington: APA; 1994.

25. Schmand B, Jonker C, Hooijer C, Lindeboom J. Subjective memory complaints may announce dementia. Neurology. 1996;46(1):121-5.
26. Wilson BA, Cockburn J, Baddeley A. The rivermead behavioral memory test. Cambridge: Thames Valley Test Company; 1991.

27. Wechsler D, Wais R. Manual. New York: The Psychological Corporation; 1981.

28. Angevaren M, Aufdemkampe G, Verhaar HJ, Aleman A, Vanhees L. Physical activity and enhanced fitness to improve cognitive function in older people without known cognitive impairment. Cochrane Database Syst Rev. 2008;16(3):CD005381. 